\title{
CORRIGENDUM
}

\section{Elucidating the chromosome 9 association with AS; CARD9 is a candidate gene}

\author{
JJ Pointon ${ }^{1,2}$, D Harvey ${ }^{1}$, T Karaderi ${ }^{1}$, LH Appleton ${ }^{1}$, C Farrar ${ }^{1}$, MA Stone ${ }^{3}$, RD Sturrock ${ }^{4}$, MA Brown ${ }^{1,5}$ \\ and BP Wordsworth ${ }^{1}$ \\ ${ }^{1}$ NIHR Oxford Musculoskeletal Biomedical Research Unit and Botnar Research Centre, Oxford, UK; ${ }^{2}$ NIHR Oxford Biomedical \\ Research Centre, John Radcliffe Hospital, Oxford, UK; ${ }^{3}$ Royal National Hospital for Rheumatic Diseases, Bath, UK; ${ }^{4}$ Centre for \\ Rheumatic Diseases, Division of Immunology, Inflammation and Infection, University of Glasgow, Glasgow, UK and ${ }^{5}$ Diamantina \\ Institute for Cancer, Immunology and Metabolic Medicine, University of Queensland, Brisbane, Australia
}

Genes and Immunity (2011) 12, 319-320; doi:10.1038/gene.2011.22

Correction to: Genes and Immunity (2010) 11, 490-496; doi:10.1038/gene.2010.17

The following errors are noted:

(1) Affiliation 1 was incorrect; the correct affiliations are shown above.
(2) Page 491, column 2, paragraph 2, line 21; 'rs11145797' should read 'rs11145793'.

(3) The corrected Table 1 is shown on the next page.

The authors apologize for any inconvenience caused. 


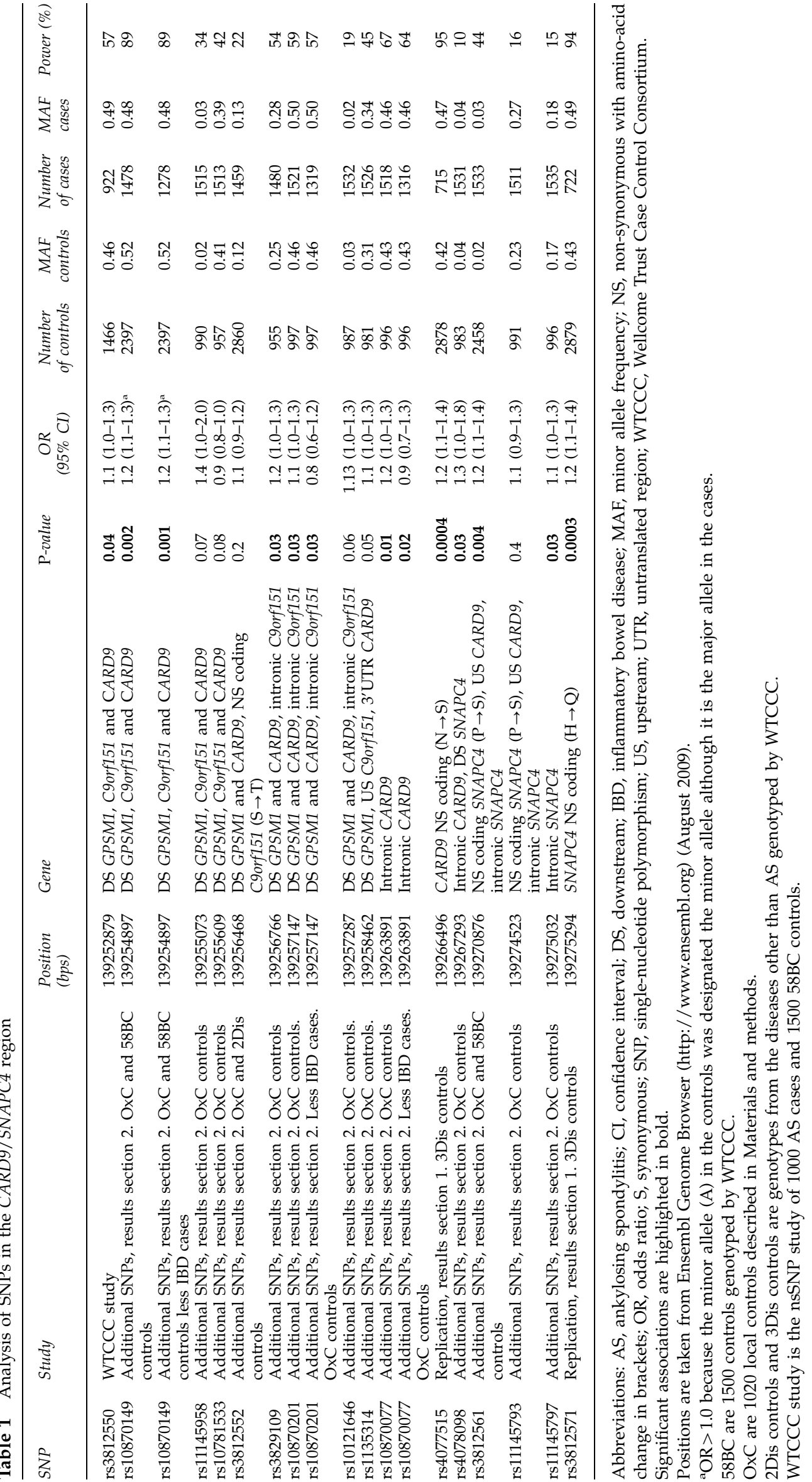

